\title{
THE EFFECTS OF CREATIVE MEDITATION ON PSYCHOLOGICAL DISTRESS AND AWARENESS CAPACITY DURING COVID 19 PANDEMIC
}

\author{
Ileana-Loredana Vitalia ${ }^{1^{*}}$
}

${ }^{1}$ Ph.D. Associate Professor, University of Pitești, Department of Psychology, Communication Sciences and Social Assistance, Pitesti, Romania

\author{
Current Trends in
}

Natural Sciences

\begin{abstract}
Creative meditation is an effective, innovative and safe psychotherapeutic intervention that may improve psychological health and well-being during the Covid 19 pandemic. Creative meditation creates a safe place for self-awareness and self-expression, allowing the discovery and development of personal resources, converting vulnerabilities into resources and facilitating personal development. The aim of the present study is to investigate the immediate effect of creative meditation on emotional distress and awareness capacity (acceptance and mindfulness). 22 students participated in a short experiment of a single online creative meditation session with pre and post surveys. An immediate significant variation in the participants' emotional experience was observed. Creative meditation helped participants to feel a positive affective state which facilitated awareness and creative emotional and cognitive expression. Statistical results revealed a decrease of general affective distress, and a lower level of negative emotions (sadness, anxiety, frightened, concerned). The personal resources could be first actualized through this emotional experience and then it could be invested into meaningful actions.
\end{abstract}

Keywords: Expressive-creative methods, mindfulness, positive emotions, psychological health.

\section{INTRODUCTION}

COVID-19 continues to generate intense psychosocial issues all around the world. One of the major concerns remains the development of more adequate and efficient methods to approach psychological distress and the complexity of mental health issues from a multitude of perspectives related to cultural, social and economic factors.

Psychologycal impact of Covid 19 pandemic continues to remain the focus of research, and studies developed in many countries emphasize the need to consider the psychological health and wellbeing (physical, economic, social, mental, emotional, psychological, spiritual, development and engaging activity, quality of life, life satisfaction and domain-specific satisfaction) of the population (Castellano-Tejedor et all, 2021; Farris et all, 2021; Mukhtar, 2020) and the development of coping resources through proactive psychological interventions (Gurvich et all, 2020; Mana et all, 2021). Using an online-based survey on 413 community adults from Spain, Castellano -Tejedor at all (2021) explored the psychological impact of Covid-19 pandemic and identified the health status of the loved ones, uncertainty about the future and being a carrier and infecting others as the main worries. These worries could cause high levels of emotional distress and thus, worsen the psycho- 
affective state and the self-perceived health status of people. This study suggested that the greater psychological impact was suffered by women and vulnerable populations such as the youngest and the elderly. Gurvich et all (2020) reported similar results from a large sample of 1,495 Australian adults and they identified positive reframing, acceptance and humour as coping strategies associated with better mental health.

In a complex review examining the interventions to optimize mental health outcomes and well being during the Covid pandemic, Safieh et all (2021) identified preventative interventions (public health education, modified social media use, technology-based interventions, physical activity, policy adaptations, and therapeutic interventions), treatment strategies (adapting existing treatment and the creation new treatment programmes and platforms) and other interventions (legislation and health system interventions). Other studies (Elisondo, 2021) considered creative activities as resilient skills in facing the psychological distress (sadness, uncertainty, stress, anxiety, anger, frustration, and fear) associated with the adverse situation of the pandemic.

More innovative strategies need to be developed to address the current mental health issues and to design person-centered interventions. Mindfulness, creative meditation and expressive-creative interventions received a great interest in the last two years.

Farris et all. (2021) emphasized the online mindfulness interventions as convenient and safe interventions to improve depression, anxiety, and general well-being. At a time of uncertainty, chaos, and distress these interventions offer momentary improvements in state function (reducing pandemic-induced elevations in state anxiety) while potentially creating new frameworks for processing stress, enhancing resilience, and increasing self-compassion and concern for others. These interventions are efficient for the healthcare workers as well, because it increase happiness and wellbeing by cultivating self-compassion and reducing burnout. The value of creative meditation had been demonstrated in many studies (Raban-Motounu, 2019; Vitalia 2019) with major effects in alleviating psychological pain and sufferance, in the expansion of the awareness field, for changing the perspective over oneself (Mitrofan, 2004) and ,,allowing the discovery and development of previously unconscious resources, thus converting past negative experiences into pretexts for personal development, vulnerabilities into resources" (Raban-Motounu, 2019, p.191).

The present study aims to investigate the immediate effect of creative meditation on emotional distress and awareness capacity (acceptance and mindfulness).

Hypothesis: 1. General affective distress would decrease after a single online creative meditation session. 2. Functional fear, dysfunctional anxiety, functional sadness and dysfunctional depression would decrease after a single online creative meditation session. 3. Awareness and acceptance would increase after a single online creative meditation session.

\section{MATERIALS AND METHODS}

Method: The present study is based on an experimental design.

The main dependent variable was general affective distress. Other dependent variables were: dysfunctional anxiety, functional sadness and dysfunctional depression, awareness and acceptance capacity. The independent variable was the participation on the online creative meditation session. Psychometrical methods (The Profile of Affective Distress (PAD), and Statistical methods were used in this study.

The Profile of Affective Distress (PAD). The scale offers a general distress score, a positive emotions score and separate scores for functional fear, dysfunctional anxiety, functional sadness and dysfunctional depression. The internal consistency of the scale has received support in previous 
studies on Romanian population with alpha Cronbach's between 0.80 and 0.94 and it is considered an efficient instrument to assess affective distress on non-clinical population.

Philadelphia Mindfulness Scale (PHLMS) assesses mindfulness on two subscales, Acceptance and Awareness. The internal consistency on a Romanian sample was 0,78.

Participants: 22 psychology students participated in this online experiment, as a part of their activity on a psychotherapy course. 20 of them were female and 1 was male.

Procedure: For this creative meditation we used guidelines from Mitrofan (2004) and Redderman (2010, cit in Beblo, 2018). The participants were asked to sit in an upright position and to allow their eyes to close gently noticing how they were sitting in the chair, where they were touching the chair, the floor, noticing where the air was touching their skin and what that felt like. The researcher asked them to imagine they are on a travel, being loaded with heavy baggage. Next, they were guided to pay attention to the specific landscape, and to the characteristics of their path (the shape, the texture) while being aware of their needs, sensations, emotions and thoughts. As the journey continued, the participants could take a few moments to rest, deciding to put down their baggage, exploring their sensations and emotions. Not far away, they discover a place with warm, bright light, a very beautiful and special place (could be their favorite place in nature, or it could be an imaginary place). The participants were provoked to move closer to it and to visually explore it paying attention to the colors, the smells, the sounds, and being aware of their needs, sensations, emotions and thoughts and to connect to their deepest resources. After a few minutes of personal silent exploration, the participants were guided to come back on their baggage using their needs and resources to consider the importance of this baggage in the present. At the end, each participant shared the experience to the group and gave details about the resources and present needs. Each participant completed ratings about the current affective state before and after this creative meditation session.

\section{RESULTS AND DISCUSSIONS}

Statistical analysis was performed to test the hypothesis of this study. Paired-Samples T Test was used to identify the differences of PAD and PHLMS scores before and after the online creative meditation. Statistical results revealed significant differences for: general affective distress $(\mathrm{t}=2.541, \mathrm{p}<0.05)$, dysfunctional anxiety $(\mathrm{t}=2.224, \mathrm{p}<0.05)$, functional sadness $(\mathrm{t}=3.673, \mathrm{p}<0.01)$, and dysfunctional depression $(\mathrm{t}=4,482, \mathrm{p}<0.01)$. There were no statistical differences considering acceptance and awareness capacity.

\begin{tabular}{|l|l|l|}
\multicolumn{4}{|c}{ Table 1: Group Statistics } \\
\hline Variable & Mean & Std. Deviation \\
\hline general affective distress & Before 85,45 & 15.07 \\
\cline { 2 - 3 } & After 79,13 & 18.66 \\
\hline \multirow{2}{*}{ dysfunctional anxiety } & Before 11,09 & 3.16 \\
\cline { 2 - 3 } & After 9,18 & 2.93 \\
\hline \multirow{2}{*}{ functional sadness } & Before 11,13 & 4.97 \\
\cline { 2 - 3 } & After 9,90 & 5.56 \\
\hline \multirow{2}{*}{ dysfunctional depression } & Before 11,09 & 4.01 \\
\cline { 2 - 3 } & After 9,95 & 3.15 \\
\hline
\end{tabular}

\section{Discussions:}

An immediate significant variation in the participants' emotional experience was observed. Creative meditation helped participants to feel a positive affective state of calm and relaxation which 
facilitated creative emotional experience and cognitive expression. Statistical results revealed a decrease of general affective distress, and a lower level of negative emotions (sadness, anxiety, frightened, concerned). The personal resources could be first actualized through this emotional experience and then it could be invested into proactive coping strategies. These results are supported by other studies (Elisondo, 2021, Farris et all., 2021) that indicated a predominance of negative emotions and affective distress (sadness, uncertainty, stress, anxiety, anger, frustration, and fear) during the last two pandemic years. We highlight the value of creativity as a resilience factor in the development of new personal experiences. It is very important to mention that the development of awarreness and acceptance capacity require a longer process of inner exploration and development.

\section{CONCLUSIONS}

Present findings indicate the positive effects of creative meditation on emotional experience, considering general affective distress, and negative emotions (dysfunctional anxiety, dysfunctional depression). Longer interventions of creative meditation need to be developed to address the negative impact of Covid pandemic of mental health.

\section{REFERENCES}

Beblo, T., Pelster, S., Schilling, C., Kleinke, K., Iffland, B., Driessen, M., Fernando, S. (2018). Breath Versus Emotions: The Impact Of Different Foci Of Attention During Mindfulness Meditation On The Experience Of Negative And Positive Emotions. Behavior Therapy, 49, 702-714.

Castellano-Tejedor, C., Torres-Serrano, M., Cencerrado, A. (2021). Psychological Impact In The Time Of Covid-19: A Cross-Sectional Population Survey Study During Confinement. Journal Of Health Psychology, 1-16, DOI: 10.1177/1359105320985580, Journals.Sagepub.Com/Home/Hpq.

Elisondo, R.C. (2021). Creative Activities, Emotions, And Resilience During The Covid-19 Pandemic: A Longitudinal Study From Argentina. Public Health 195, 118-122, Https://DOI.Org/10.1016/J.Puhe.2021.04.017.

Farris, S.R., Grazzi, L., Holley, M., Dorsett, A., Xing, K., Pierce, C.R., Estave, P.M., O’connell, N., Erwin Wells, R. (2021). Online Mindfulness May Target Psychological Distress And Mental Health During Covid-19. Global Advances In Health And Medicine, 9, 1-15. Doi: 10.1177/21649561211002461. Journals.Sagepub.Com/Home/Gam.

Feruglio, S., Matiz, A., Pagnoni, G., Fabbro , F., Crescentini, C. (2021). The Impact Of Mindfulness Meditation On The Wandering Mind: A Systematic Review. Neuroscience And Biobehavioral Reviews, 131, 313-330, Https://DOI.Org/10.1016/J.Neubiorev.2021.09.032.

Gurvich, C.,Thomas, N., Thomas, E., Hudaib, A.R., Sood, L., Fabiatos, K., Sutton, K., Isaacs, A., Arunogiri, S., Sharp, G., Kulkarni, J. (2020). Coping Styles And Mental Health In Response To Societal Changes During the Covid-19 Pandemic. International Journal Of Social Psychiatry 1-10. DOI: 10.1177/0020764020961790. Journals.Sagepub.Com/Home/Isp.

Mana, A., Super, S., Sardu, C., Canal, D.J., Moran, N., Sagy, S. (2021). Individual, Social And National Coping Resources And Their Relationships With Mental Health And Anxiety: A Comparative Study In Israel, Italy, Spain, And The Netherlands During The Coronavirus Pandemic. Global Health Promotion, 0:1-10; DOI:10.1177/1757975921992957. Journals.Sagepub.Com/Home/Ghp.

Mitrofan. I. (2004). Terapia Unificării. Abordare holistică a dezvoltării si a transformării umane [Unification Psychotherapy. Holistic Approach Of The Human Development And Transformation]. Bucharest: Sper.

Mukhtar, S. (2020). Psychological Health During The Coronavirus Disease 2019 Pandemic Outbreak. International Journal Of Social Psychiatry, 66(5), 512-516. DOI:10.1177/0020764020925835. Journals.Sagepub.Com/Home/Isp.

Răban-Motounu, N. (2019). Relaxation and creative meditation centered on nature helps in activating coping mechanisms. Current Trends in Natural Sciences, 8(16), 190-195. 


\section{Current Trends in Natural Sciences}

Vol. 10, Issue 20, pp. 207-211, 2021

https://doi.org/10.47068/ctns.2021.v10i20.028

Current Trends in Natural Sciences (on-line)

ISSN: 2284-953X

Current Trends in Natural Sciences (CD-Rom)

ISSN-L: 2284-9521

ISSN: 2284-9521

Safieh, J., Broughan, J., McCombe, G., Mccarthy, N., Frawley, T., Guerandel, A., Lambert, Js., Cullen, W. (2021). Interventions To Optimise Mental Health Outcomes During The Covid-19 Pandemic: A Scoping Review. International Journal Of Mental Health And Addiction. Https://DOI.Org/10.1007/S11469-021-00558-3.

Vitalia, I.L. (2019). The breath - the experience of being present. Current Trends in Natural Sciences, 8(16), 196-199. 